\title{
Dry-Resistance of Salmonella enterica subsp. enterica Serovar Enteritidis is Regulated by Both SEp22, a Novel Pathogenicity-Related Factor of Salmonella, and Nutrients
}

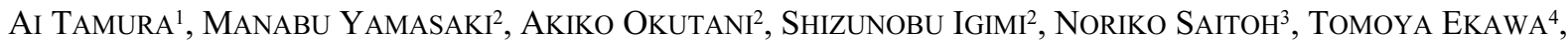 \\ Hiroyuki OHTA ${ }^{4}$, YOKO KATAYAMA ${ }^{5}$, and FUMIO AMANO ${ }^{*}$ \\ ${ }^{1}$ Laboratory of Biodefense \& Regulation, Osaka University of Pharmaceutical Sciences, 4-20-1 Nasahara, Takatsuki, \\ Osaka 569-1094, Japan; ${ }^{2}$ Division of Biomedical Food Research, National Institute of Health Sciences, 1-18-1 \\ Kamiyoga, Setagaya-ku, Tokyo 158-8501, Japan; ${ }^{3}$ Laboratory of Electron Microscopy, National Institute of Infectious \\ Diseases, 1-23-1 Toyama, Shinjuku-ku, Tokyo 162-8640, Japan; ${ }^{4}$ CAF Laboratories, Inc., 1257-1 Michinoue, \\ Kannabe-cho, Fukuyama, Hiroshima 720-2104, Japan, and ${ }^{5}$ Laboratory of Environmental Microbiology, Faculty \\ of Agriculture, Tokyo University of Agriculture \& Technology, 3-5-8 Saiwai-cho, Fuchu, Tokyo 183-8509, Japan
}

(Received February 1, 2009—Accepted March 4, 2009—Published online, March 31, 2009)

Environmental isolates of Salmonella enterica serover Enteritidis ( $S$. Enteritidis) clones were grown to the logarithmic phase, washed and re-suspended in saline or Luria-Bertani (LB) medium, and then 10- $\mu \mathrm{L}$ aliquots of the suspensions were dried overnight at room temperature. The dried bacteria were mixed with $1 \mathrm{~mL}$ of ice-cold PBS, suspended and examined for colony-forming activity. All of the pathogenic clones with high levels of SEp22, identical to Salmonella Dps, maintained good viability if suspended in LB medium prior to drying. However, none of the nonvirulent strains, exhibiting low levels of SEp22, survived. Similar results were obtained with sep22-knocked out mutants, suggesting that SEp22 is important for the acquisition of dry-resistance. Nutritional factors, such as LB medium, cabbage extracts, and egg yolk but not egg white, were shown to be necessary for the acquisition of dry-resistance, because none of the clones remained viable irrespective of SEp22 expression if suspended in saline. Scanning electron micrograms also supported the importance of nutrition, showing re-growth of the bacteria after drying in LB but not in saline. These results suggest the importance of both SEp22 expression and nutrients for the acquisition of dryresistance by $S$. Enteritidis.

Key words: Salmonella Enteritidis, dry-resistance, nutrition, SEp22 (Salmonella Dps), viability

Salmonella enterica serover Enteritidis ( $S$. Enteritidis), often causative of food-borne diseases in Japan, is detected not only in food but also in natural environments including river water, soil and air-borne dust. Recent reports found vegetables like cabbages, tomatoes and pimentos to be contaminated by $S$. Enteritidis and the likely cause of mass foodpoisoning in Japan (18) and the United States (5). To control the spread of $S$. Enteritidis to foods, it seems important to determine those characteristics that allow it to survive in natural environments. Dry-resistance is one of the most remarkable means by which Salmonella protects itself from stressful conditions $(10,19,20)$, although both the mechanism underlying its acquisition and its distribution in Salmonella spp. are poorly understood. To date, dry-resistant phenotypes of Salmonella have been studied in relation to food-protection $(3,4,12,23)$, biofilm formation (2), morphological changes $(11,25,26)$ and stress responses $(9,12)$. Many of these studies have focused on changes in a viable but non-culturable state $(12,14)$, including aggregation $(26)$, fimbriae and cellulose (24), or lipopolysaccharide $(6,7)$. However, the assay systems used in these experiments require a long incubation period before any estimation of changes. In addition, the molecules and genes in Salmonella responsible for these

\footnotetext{
* Corresponding author. E-mail: amano@gly.oups.ac.jp; Tel: +8172-690-1054; Fax: +81-72-690-1054.
}

changes have not been fully elucidated, except for AgfD involved in the regulation of the $O$-antigen capsule's formation (7), and AgfB involved in the development of fimbriae (26).

In the course of studying the pathogenicity of environmental isolates of $S$. Enteritidis, we happened to find that SEp22, a novel pathogenicity-related factor (21), identical to Salmonella Dps (8) (Amano et al., manuscript in preparation), plays a critical role in the establishment of resistance to dry-stress. Because Dps is a DNA-binding protein (1) reported to be involved in the protection of DNA from $\mathrm{H}_{2} \mathrm{O}_{2}$, heat and chemicals $(15,27)$, it is worth studying the roles of SEp22 in the protection of Salmonella from dry-stress. In this report, we present evidence that SEp22 is involved in the acquisition of dry-resistance by $S$. Enteritidis, and that nutritional factors are also required.

\section{Materials and Methods}

\section{Bacterial culture}

Environmental isolates of $S$. Enteritidis, obtained from CAF Laboratories (Fukuyama, Hiroshima, Japan) (21), were used. The sep22 deletion mutants were constructed previously (Amano et al., manuscript in preparation), following the method of Miki et al. (16), in which the open reading frame of sep 22 was replaced with an aph cassette. The bacterium was cultured overnight in $10 \mathrm{~mL}$ of LuriaBertani (LB) medium (Difco ${ }^{\mathrm{TM}}, \mathrm{BD}$, Sparks, MD, USA), in a $50-$ 
$\mathrm{mL}$ tube at $37^{\circ} \mathrm{C}$, with shaking at 150 strokes $\mathrm{min}^{-1}$. It was then suspended in fresh LB medium at $\mathrm{OD}_{550}=0.05 \mathrm{~mL}^{-1}$, and cultured at $37^{\circ} \mathrm{C}$ for $105 \mathrm{~min}$ until its growth reached a mid-logarithmic phase. The bacterium was chilled on ice, harvested by centrifugation at $4,120 \times \mathrm{g}$ for $20 \mathrm{~min}$ at $4^{\circ} \mathrm{C}$, washed twice with $10 \mathrm{~mL}$ of ice-cold phosphate-buffered saline (PBS), $\mathrm{pH} 7.5$, and finally suspended in ice-cold saline $\left(0.85 \% \mathrm{NaCl}\right.$ in $\left.\mathrm{H}_{2} \mathrm{O}\right)$ at about $1 \times 10^{8} \mathrm{cfu} \mathrm{mL}^{-1}(22)$.

\section{Assaying of dry-resistance}

Ten microliters of the washed bacterial suspension was mixed on ice with various amounts of LB, nutrients, or saline in a final volume of $1 \mathrm{~mL}$, and $10 \mu \mathrm{L}$ of each bacterial mixture containing about $1 \times 10^{6} \mathrm{cfu}$ was placed at the bottom of a $50-\mathrm{mL}$ sterile centrifugation tube equipped with a sterile $0.45-\mu \mathrm{m}$ pore-filtered cap (Techno Plastic Products AG, Trasadingen, Switzerland). The tubes were dried at room temperature under $25-40 \%$ humidity in an automatic dry-keeper (Sanko Plastic, Osaka, Japan) for a few hours or days. The dry-resistance assay was terminated by the addition of $1 \mathrm{~mL}$ of ice-cold PBS to the centrifugation tube, which was vigorously vortexed for $15 \mathrm{~s}$ twice and then placed in an ice-bath for more than 15 min to allow complete recovery of the dried bacteria in the PBS solution. Finally, the bacterial solution was serially diluted with icecold PBS, and then $25-\mu \mathrm{L}$ aliquots of the resulting solution were plated onto LB-agar plates and incubated overnight at $37^{\circ} \mathrm{C}$. The number of resultant colonies was determined and used as the viable bacterial cell count (cfu).

\section{Preparation of bacterial cell extracts}

The culturing of bacteria was performed at $37^{\circ} \mathrm{C}$, with shaking at 150 strokes min $^{-1}$ overnight as described above. The cells were chilled on ice, and collected by centrifugation at $4,120 \times \mathrm{g}$ for $20 \mathrm{~min}$ at $4^{\circ} \mathrm{C}$. The cell precipitates were suspended in $10 \mathrm{ml}$ of icecold PBS, centrifuged again, and finally suspended in PBS at $\mathrm{OD}_{550}=10 \sim 20$ prior to use. The washed cells were disrupted with 0.1 g of glass beads (Sigma, St. Louis, MO, USA) in a Cell Beater (BIO 101, Fast Prep ${ }^{\mathrm{TM}}$ FP120, Thermo Savant, Holbrook, NY, USA) and centrifuged at $40,300 \times \mathrm{g}$ for $5 \mathrm{~min}$ at $4^{\circ} \mathrm{C}$. The supernatant was collected as the bacterial cell extract (21).

\section{SDS-PAGE/Western blotting}

$S$. Enteritidis extracts containing the same amount of protein were loaded onto 5-20\% polyacrylamide Slab gels (e-PAGEL ${ }^{\mathrm{TM}}$; ATTO, Tokyo, Japan) and electrophoresed using the discontinuous buffer system of Laemmli (13). The separated proteins were electro-transferred to PVDF membranes (Immobilon $\mathrm{P}^{\mathrm{TM}}$; Millipore, Bedford, MA, USA), which were blocked with $30 \mathrm{mg} \mathrm{mL}^{-1}$ of milk casein (Snow Brand, Sapporo, Japan) in a rinse buffer $(0.1 \%$ Triton $\mathrm{X}-100$ in $10 \mathrm{mM}$ Tris-HCl, $0.1 \mathrm{mM}$ EDTA and $0.8 \% \mathrm{NaCl}, \mathrm{pH} 7.5$ ), and then reacted with a polyclonal anti-SEp22 antibody raised in rabbits at $37^{\circ} \mathrm{C}$ for $2 \mathrm{~h}(22)$. The membrane was washed three times with the rinse buffer and incubated with HRP-conjugated anti-rabbit IgG (Cell Signaling Technology, Danvers, MA, USA) for $1 \mathrm{~h}$ at room temperature. Finally, immune complexes on the membrane were reacted with luminol and $\mathrm{H}_{2} \mathrm{O}_{2}$, according to the manufacturer's directions (Cell Signaling Technology) (21).

\section{Quantitative analysis of SEp22}

The chemiluminescence associated with each protein was detected with an LAS1000 bioimage analyzer (Fuji Film, Tokyo, Japan) and the image was quantitatively analyzed with Multi Gauge software (version 2.2; Fuji Film) (21). The level of SEp22 in each cell extract was estimated quantitatively at least three times with independent samples from different experiments.

\section{Preparation of nutritional additives}

To prepare the nutritional additives, cabbages were obtained from an agrochemical-free farm and $7.63 \mathrm{~g}$ of the fresh raw cabbage leaf was mixed with $10 \mathrm{~mL}$ of distilled water, and homogenized with a mixer. One volume of the homogenate was mixed with 4 vol- umes of saline, and the mixture was subjected to aseptic filtration through a $0.45-\mu \mathrm{m}$ pore membrane (Iwaki, Tokyo, Japan). Also, fresh raw eggs, laid by vaccine-free SPF hens, were collected, washed, and ruptured to separate the egg yolk and egg white. One volume of each was mixed with 4 volumes of saline, and homogenized by sonication. The homogenates were aseptically filtered through $0.45-\mu \mathrm{m}$ pore membrane filters. These materials were kept frozen at $-30^{\circ} \mathrm{C}$ until used in the dry-resistant experiments.

\section{Electron microscopy}

Morphological changes of $S$. Enteritidis after the dry-protocol were observed by scanning electron microscopy. In brief, $1 \times 10^{4} \mathrm{cfu}$ of $S$. Enteritidis in $10 \mu \mathrm{L}$ of LB or saline was laid onto cover glasses, and then dried in sterile $50-\mathrm{mL}$ centrifuge tubes with filter caps as described above, at room temperature overnight. Half of the samples were directly fixed in $1 \mathrm{~mL}$ of ice-cold $2 \%$ paraformaldehyde in PBS containing 0.2 M sucrose, and the rest were incubated individually in fresh LB medium at $37^{\circ} \mathrm{C}$ for $4 \mathrm{~h}$, then fixed as described above. After the fixation at $4^{\circ} \mathrm{C}$ overnight, the samples were fixed again with $2.5 \%$ glutaraldehyde and $2 \%$ paraformaldehyde in PBS containing $0.2 \mathrm{M}$ sucrose at room temperature for 30 min. Alternatively, $10 \mu \mathrm{L}$ of the control sample without the dry-protocol was laid onto poly-L-lysine-coated cover glasses, stood for 30 $\min$ at $4^{\circ} \mathrm{C}$ on ice, and then fixed directly with $1 \mathrm{~mL}$ of ice-cold $2 \%$ paraformaldehyde in PBS containing $0.2 \mathrm{M}$ sucrose. This was followed by the protocols described above. Finally, all of the samples were washed with PBS and processed by dehydration with an ascending acetone series. The specimens were subjected to critical point drying with a liquid $\mathrm{CO}_{2}$ dryer (HCP-2 type; Hitachi, Tokyo, Japan), coated with osmium with a model Neoc-ST osmium plasma coater (Meiwaforsis, Osaka, Japan), and then examined under a scanning electron microscope (Model S-5200; Hitachi).

\section{Other assays and methods}

Protein concentrations were determined with a Protein assay reagent (Bio-Rad, Hercules, CA, USA) using bovine serum albumin (Fraction V; Sigma) as a standard (21).

\section{Results}

\section{Establishment of an assay for Salmonella dry-resistance}

In this study, we first established an assay for Salmonella dry-resistance at room temperature with an automatic drykeeper. This method is easy to perform and suitable for keeping the humidity in the chamber below $40 \%$ for long periods with large numbers of samples in filter-capped tubes. Samples composed of $10 \mu \mathrm{L}$ of the bacterial suspension in the tubes had usually lost their fluidity by $6 \mathrm{~h}$ and become dried up by $8 \mathrm{~h}$. The addition of ice-cold PBS to the dried samples and subsequent vigorous mixing with a vortex mixer led to a high rate of recovery of the bacteria from the centrifuge tubes. As shown in Fig. 1A, SECl\#15-1, a wild-type virulent strain, survived in considerable numbers for 7 days after the dry-protocol, when the bacteria were suspended in LB medium initially. The transient increase in cfu on day 1 was probably caused by cell division in LB medium for several hours after the start of the incubation of logarithmically grown bacteria exhibiting high replication efficiency at room temperature, which was supported by the results in Fig. 1B, although these results were obtained with another $S$. Enteritidis strain, a KO-5 mutant.

\section{Involvement of SEp22 in the acquisition of Salmonella dry-resistance}

In the course of studying dry-resistance, we happened to 
(A)

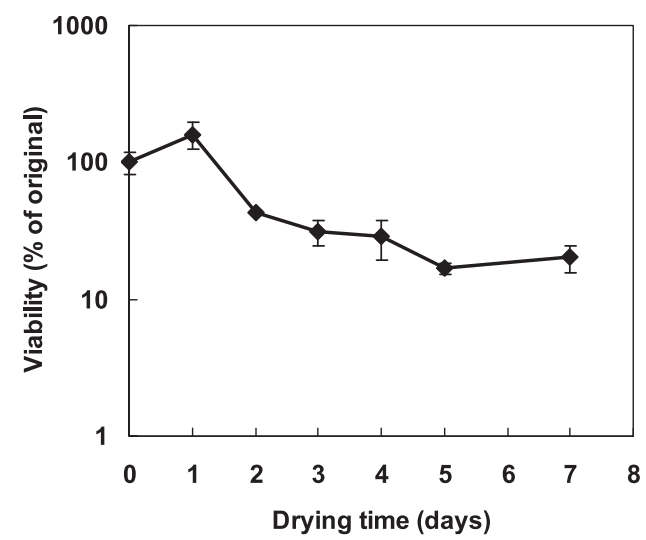

(B)

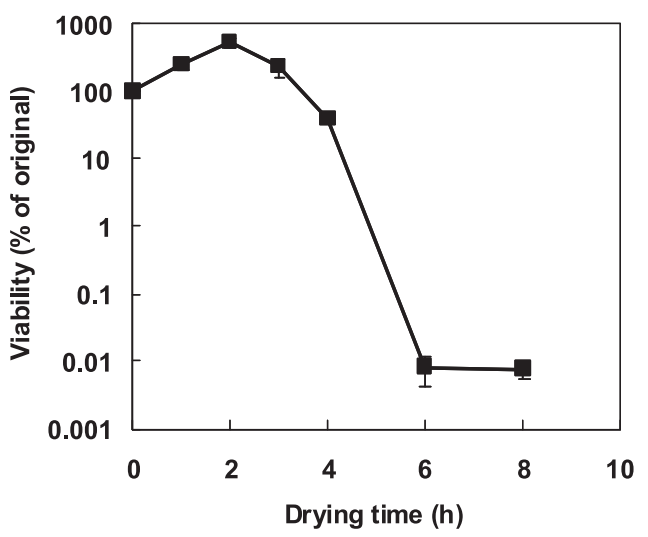

(A)

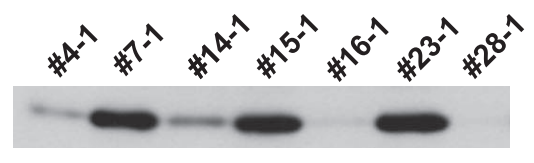

(B)

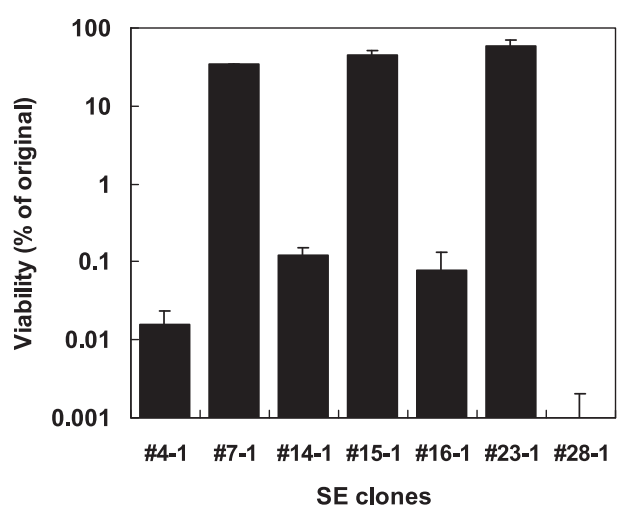

Fig. 2. Expression of SEp22 and dry-resistance in Salmonella environmental isolates. (A) Expression of SEp22 proteins in Salmonella Enteritidis clones isolated from poultry farms. The cells were cultured in LB medium at $37^{\circ} \mathrm{C}$ overnight, washed and then homogenized. Thirty-microgram aliquots of the homogenate's proteins were loaded onto SDS-slab gels, and analyzed by Western blotting with an antiSEp22 antibody, as described in the text. Each band corresponds to SEp22 of MW $18.7 \mathrm{kDa}$. (B) Dry-resistance of the Salmonella Enteritidis clones. The cells were cultured in LB medium to the midlogarithmic phase, washed and suspended in fresh LB medium, and then treated with the dry-protocol for $24 \mathrm{~h}$, as described in the legend to Fig. 1 . The results are shown as relative viability (\%), as in Fig.1, and are the mean \pm SD for duplicate samples from one of several experiments.

Fig. 1. Dry-resistance of the SECl\#15-1 wild-type and a sep22-KO mutant of Salmonella in LB medium. A Salmonella Enteritidis clone, SECl\#15-1, was used as a wild-type parental strain (A) and a sep22knocked out mutant, KO-5 (B), was also used in this experiment. The bacteria were precultured in LB, washed and suspended in fresh LB, and then treated with the dry-protocol for 7 days (A) or $8 \mathrm{~h}$ (B), as described in the text. The number of colonies was determined after incubation overnight at $37^{\circ} \mathrm{C}$. Results are shown as viability relative to the control, taking the initial number of viable bacteria as $100 \%$. The results are shown as the mean \pm SD for duplicate samples from one of several repeated experiments.

find that a sep22-knocked out mutant strain, KO-5, did not survive for $24 \mathrm{~h}$ under the same conditions as SECl\#15-1 (data not shown). A further experiment with shorter timecourses revealed that cell number of the KO-5 mutant increased temporarily at $2 \mathrm{~h}$, then decreased gradually for 2 $4 \mathrm{~h}$ and very rapidly after $4 \mathrm{~h}$, and reached the basal level, below $0.01 \%$ of the original count, $6 \mathrm{~h}$ after the start of the dry-protocol (Fig. 1B). A control strain of KO-5, in which the open reading frame of a gene other than sep 22 was replaced with the aph cassette (16), survived similarly to the wild-type, parental clone SECl\#15-1 (data not shown), suggesting that sep 22 is involved in the acquisition of dry-resistance by $S$. Enteritidis.

To substantiate this hypothesis, we examined SE clones isolated from poultry farms in Japan, and coordinated the expression of the SEp22 protein. As shown in Fig. 2A, there were major differences among the clones in the amount of SEp22 relative to that in SECl\#15-1 (100\%); SECl\#4-1, 7.43\%, \#7-1, 101.47\%, \#14-1, 12.69\%, \#16-1, 2.82\%, \#23-1, $111.90 \%$, and \#28-1, 2.12\%. The clones that expressed large

amounts of SEp22, such as SEC\#7-1, \#15-1 and \#23-1, survived at levels that were more than $10 \%$ of the initial cell number (Fig. 2B). However, those that expressed very small amounts of SEp22, such as SECl\#4-1, \#14-1, \#16-1, and \#28-1, survived at less than $0.1 \%$ of the initial cell number (Fig. 2B), supporting the findings in Fig. 1, and the idea that SEp22 is involved in the acquisition of dry-resistance by $S$. Enteritidis.

Similar results were obtained with sep22-knocked out mutants other than KO-5 (Fig. 3). KO-2, -3, and -4, independent mutant clones derived from SECl\#15-1, did not contain SEp22, as was the case for KO-5 (Fig. 3A), and the numbers of these mutant clones surviving after the dry-protocol were never more than $0.01 \%$ of the initial values (Fig. 3B). In this experiment, we compared the dry-resistance of the mutants with that of SECl\#15-1, the parental strain of these mutants, and also with that of SECl\#16-1, an environmental isolate exhibiting weak SEp22 protein expression (Fig. 2A), and weak SEp22 mRNA expression, but with the same sep22 gene as SECl\#15-1 (21). Results similar to those in Fig. 2 were obtained, indicating a close but not exact correlation between the amount of SEp22 and the extent of dry-resistance, especially for small amounts of SEp22.

\section{Impaired acquisition of dry-resistance by SECl\#15-1 suspended in saline}

When the experiments were performed with SECl\#15-1 suspended in saline, dry-resistance was not acquired, and the time-dependent changes in the numbers of this clone were 
(A)

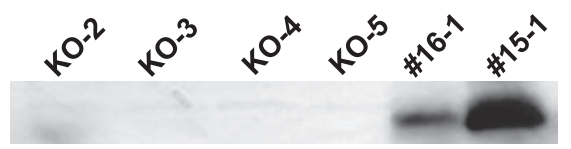

(B)

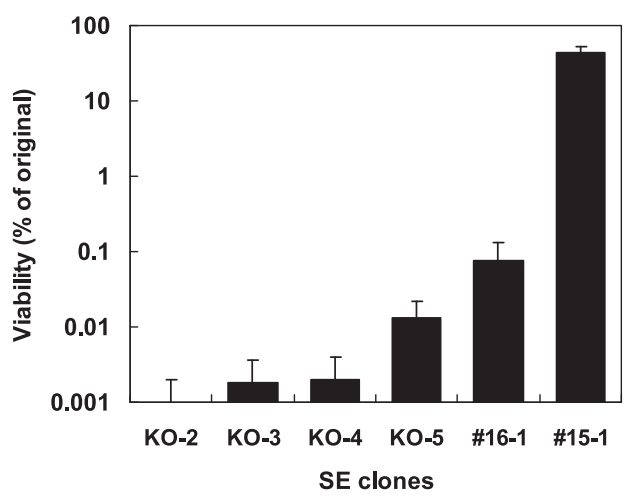

Fig. 3. Dry-resistance of sep22-knocked out mutants of Salmonella Enteritidis. (A) Expression of SEp22 proteins in sep22-knocked out mutants of Salmonella Enteritidis, derived from SECl\#15-1. Independent clones of sep22-knocked out mutants, $\mathrm{KO}-2,-3,-4$ and -5 , were grown in LB medium at $37^{\circ} \mathrm{C}$ overnight, washed, homogenized, and then analyzed for expression of the SEp22 protein by SDS-PAGE/ Western blotting, as described in the legend to Fig. 2. As controls, SEp22 proteins from the parental strain, SECl\#15-1, and a SEp22-low expression strain derived from an environmental isolate, SECl\#16-1, are also shown. (B) Dry-resistance of sep22-knocked out mutants, SECl\#15-1 and SECl\#16-1. The cells were treated similarly to as described in the legend to Fig. $2 \mathrm{~B}$. Representative results of repeated experiments are shown.

similar to those of the KO-5 mutant suspended in saline (Fig. 4). As shown in Figs. 1A and 1B, there was a marked difference between these two $S$. Enteritidis clones with or without SEp22 in the acquisition of dry-resistance when they were suspended in LB. These results suggest that not only SEp22 but also nutritional factors like the contents of the LB medium are necessary for the acquisition of dry-resistance by $S$. Enteritidis. These results also imply that dry-resistance in Salmonella is regulated by sep 22 gene expression and by nutritional factors.

\section{Morphological changes of Salmonella during the dry-protocol and subsequent incubation in LB medium}

In addition to the changes in viability, we focused on the morphological changes of $S$. Enteritidis during the dry-protocol, especially in the presence or absence of LB medium, because the survival of Salmonella seems to be greatly influenced by nutritional factors in the environment. As shown in Fig. 5A, the control SECl\#15-1 grown in LB medium in the logarithmic phase exhibited healthy, rod-shaped structures with flagella. The cells suspended in LB medium looked intact even after the dry-protocol overnight, although the surface of the bacterium was somewhat shrunken (Fig. 5B). However, they turned out to be significantly damaged by the dry-protocol, and were ruptured with pits in and protrusions like fimbriae from the membrane, when suspended in saline before drying (Fig. 5C). These results seem to correlate well with the changes in numbers in Figs. 1 and 4, showing that the maintenance of numbers in LB medium (Fig. 1) and the

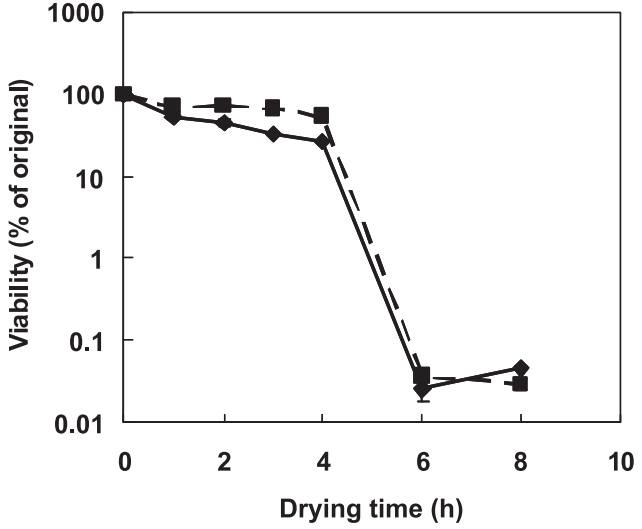

Fig. 4. Impaired acquisition of dry-resistance by the Salmonella Enteritidis wild-type and a sep22-knocked out mutant in saline. A Salmonella Enteritidis clone, SECl\#15-1 (solid line), and its sep22knocked out mutant, the KO-5clone (dashed line), were examined for dry-resistance suspended in saline. The cells were treated as described in the legend to Fig. 1, except for the medium used to suspend the cells before the dry-protocol. In this experiment, the cells were harvested from the cultures, washed thoroughly with ice-cold saline twice, and then suspended in saline at $1 \times 10^{8} \mathrm{cfu} \mathrm{mL}^{-1}$. The dry-protocol thereafter was similar to as in Fig. 1, and was performed for $8 \mathrm{~h}$. The results are shown as the mean \pm SD for duplicate samples from one of several experiments.

decrease in numbers in saline (Fig. 4) are based on changes in the morphology of $S$. Enteritidis.

We also examined the morphological changes of SECl\#15-1 during re-incubation of dried samples in LB medium at $37^{\circ} \mathrm{C}$ for $4 \mathrm{~h}$. The cells, dried in LB medium overnight, had extended many structures like flagella (long) and fimbriae (short) (Fig. 5D), while those dried in saline overnight extended far fewer fimbriae-like protrusions but exhibited remarkable pinching of membranes or severely damaged pits (Fig. 5E). These results suggest that the recovery from a dried up state is dependent on the nutritional supply before the dry-protocol.

\section{LB-dependent acquisition of dry-resistance by S. Enteritidis}

The results in Figs. 1 and 4 suggest that nutritional factors are required for the acquisition of dry-resistance by SECl\#15-1. Therefore, we examined the effects of LB. As shown in Fig. 6, the addition of 20\% LB in saline almost completely reversed the decrease in cfu with saline alone, and $10 \% \mathrm{LB}$ in saline was effective in maintaining the number of viable cells at more than $10 \%$ of the initial level, suggesting that even small amounts of nutritional factors greatly improved the dry-resistance of $S$. Enteritidis strains expressing SEp22 like SECl\#15-1.

\section{Effects of natural nutritional factors on the acquisition of dry-resistance by S. Enteritidis}

In natural environments, $S$. Enteritidis may come into contact with a variety of nutritional factors. We therefore examined the effects of the components of eggs and cabbage. The egg yolk and egg white were carefully separated from eggs laid by vaccine-free SPF hens. A $5-20 \%$ egg yolk solution in saline showed similar effects on the acquisition of dry-resistance to $20-100 \%$ LB medium (Fig. 7B). Moreover, egg white little increased the viability. Cabbage leaves were 

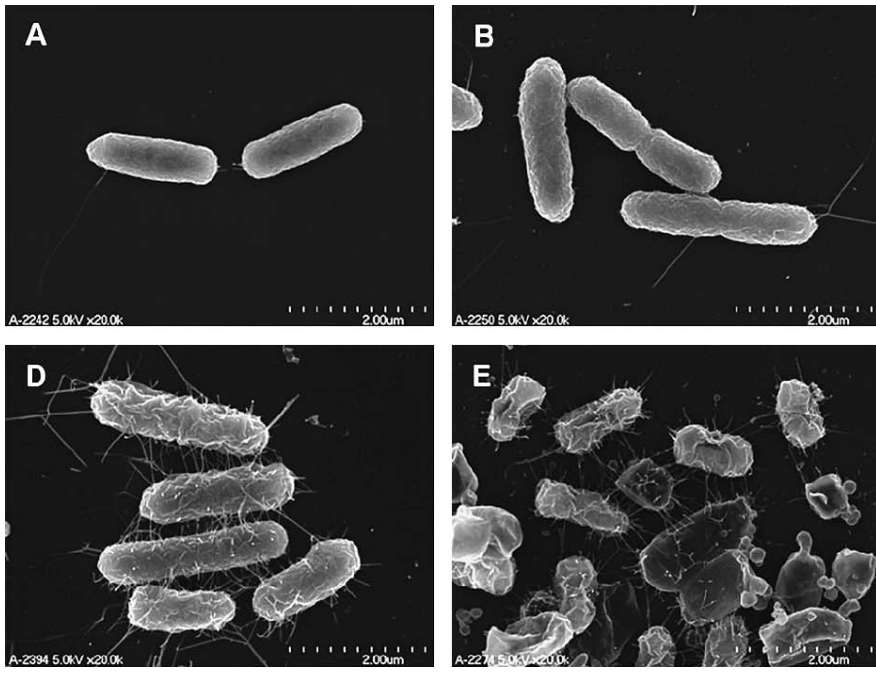

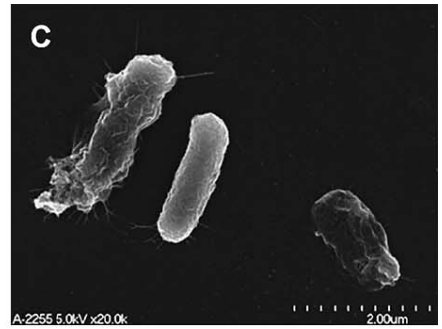

Fig. 5. Electron micrograms of Salmonella Enteritidis after the dryprotocol started with the cells suspended in LB or saline. A Salmonella Enteritidis clone, SECl\#15-1, was observed before the dry-protocol (A), or after the dry-protocol at room temperature overnight in LB medium $(B, D)$ or saline $(C, E)$ without $(B, C)$ or with subsequent re-incubation in $\mathrm{LB}$ medium at $37^{\circ} \mathrm{C}$ for $4 \mathrm{~h}(\mathrm{D}, \mathrm{E})$. Each sample was prepared and observed under a scanning electron microscope as described in the text, except that the control cells without the dry-protocol (A) were fixed directly with the fixatives. The morphological features of typical samples in random fields are shown. Magnification, $\times 20,000$; scale, $2 \mu \mathrm{m}$.

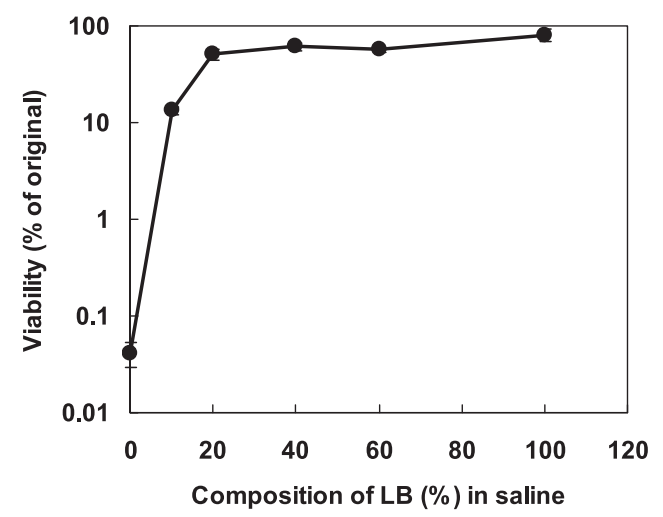

Fig. 6. Effects of LB on the acquisition of dry-resistance by Salmonella Enteritidis. SECl\#15-1 was cultured at $37^{\circ} \mathrm{C}$ overnight, harvested, washed with ice-cold saline, and then suspended in $1 \mathrm{~mL}$ of saline containing $0-100 \%$ of fresh LB medium. Finally, these suspensions with various concentrations of LB were examined as to their facilitation of the acquisition of dry-resistance according to the protocol described in the legend to Fig. 1 and in the text. The results are shown as the mean $\pm \mathrm{SD}$ for duplicate samples from one of several experiments.

obtained from an agrochemical-free farm, and homogenized aseptically. The addition of 5-20\% cabbage extracts significantly increased cfu with the dry-protocol, suggesting that the extracts maintained the viability of $S$. Enteritidis during the dry-protocol.

These results show that not only the amount but also the quality of nutrients is critical, because the original protein concentrations of the nutrient preparations used in this experiment were; egg yolk, $9.92 \mu \mathrm{g} \mathrm{mL}^{-1}$, egg white, $6.20 \mu \mathrm{g} \mathrm{mL}^{-1}$, and cabbage extracts, $0.593 \mu \mathrm{g} \mathrm{mL} \mathrm{mL}^{-1}$. It should be noted that the protein patterns of these nutrients were quite different (Fig. 7A), suggesting great variety in nature, and thus nutritional factors are not limited to the components examined in this experiment.

\section{Discussion}

In this study, we established an assay for evaluating the dry-resistance of Salmonella at room temperature. The method involves simple techniques and materials, with good control with an automatic dry-keeper that keeps the humidity inside the chamber below $40 \%$. In contrast to methods requiring the spraying of Salmonella onto heated dry corn flour (23), the immersion in Pseudomonas syringae of plant leaves (17), and inoculation onto cotton lint and a glass plate (9), our experimental system provides simple, rapid, and reproducible results. Recently, we examined the dry-resistance of bacteria other than Salmonella such as Enterobacter sakazakii using this method, and obtained reproducible results under various conditions (Naruse et al., manuscript in preparation). Therefore this assay system seems to be useful for estimating bacterial dry-resistance in general.

Using this method, we examined the dry-resistance of an environmental isolate of $S$. Enteritidis, SECl\#15-1, and found that the clone was dry-resistant, with more than $20 \%$ of the bacteria initially suspended in LB medium and then dried at room temperature for 7 days surviving (Fig. 1A). We found two important requirements for the acquisition of dryresistance; the expression of SEp22, and the presence of nutritional factors.

The need for SEp22 expression was suggested by the finding that neither sep22-knocked out mutants, including the KO-5 strain, (Figs. 1, and 3), nor environmental isolates with low levels of SEp22 (Fig. 2) survived the dry-protocol particularly well. These results show the close correlation between the acquisition of dry-resistance by $S$. Enteritidis and expression of the SEp22 protein, but not the sep22 gene itself, because cloning of the gene in SECl\#16-1, with a much lower level of the SEp22 protein than SECl\#15-1 (Fig. 2A), revealed no difference in the nucleotide sequence with SECl\#15-1 (21).

Although the precise mechanisms behind dry-resistance remain unknown, the role of SEp22 protein in the acquisition of dry-resistance by $S$. Enteritidis seems to be three-fold; reducing cell damage during loss of water from the cells, maintaining a dried state free from mechanical as well as metabolic stress during the dried state, and controlling cellular metabolism and morphological changes in order to adapt from a dormant state to an active one. Given that Salmonella 
(A)

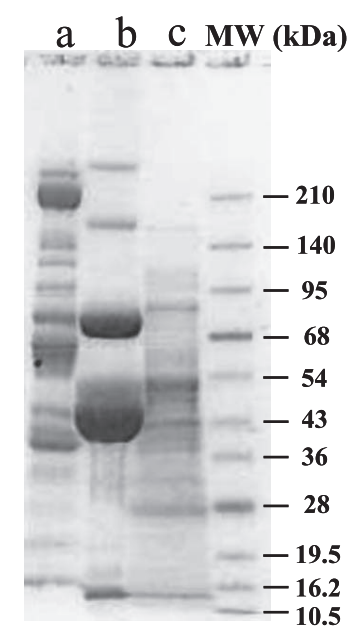

(B)

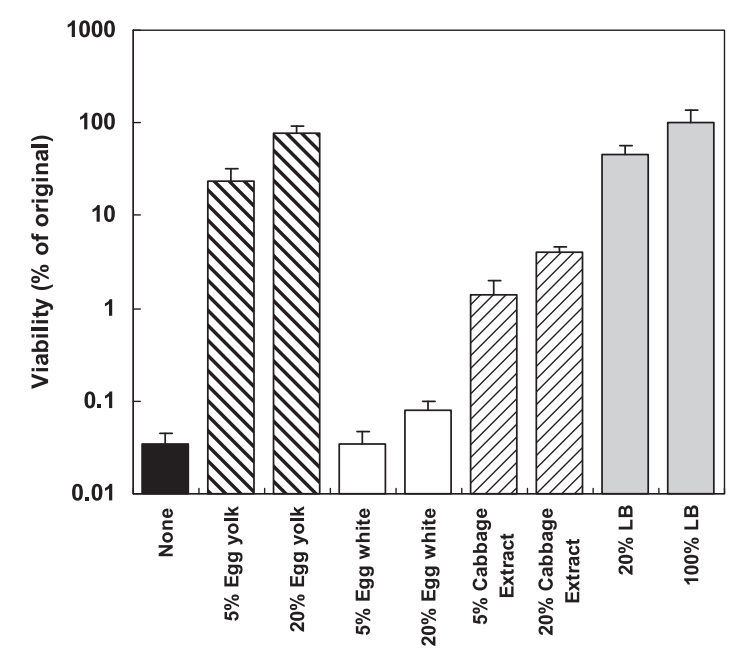

Fig. 7. Effects of nutritional additives on the acquisition of dry-resistance by Salmonella Enteritidis. (A) Staining profiles of the proteins used as the nutritional additives. Egg yolk (a), egg white (b), or cabbage extract (c), $8.3 \mu \mathrm{g}$ of protein, was loaded onto a 5-20\% gradient polyacrylamide slab gel, separated by SDS-PAGE, and stained with Coomassie Brilliant Blue. MW, protein markers of indicated molecular weights $(\mathrm{kDa})$. (B) Effects of various nutrients on the acquisition of dry-resistance. As described in the legend to Fig. 6, logarithmically grown $\mathrm{SECl \# 15-1}$ cells were prepared, washed with saline and then mixed with $1 \mathrm{~mL}$ of ice-cold saline containing various nutritional additives as shown on the abscissa, before being dried at room temperature for $24 \mathrm{~h}$. Numbers of Salmonella Enteritidis were estimated and the results are shown as relative viability (\%) compared to the original count (cfu) of each group. The results are the mean \pm SE for more than four independent experiments.

Dps (8) binds to DNA and accumulates iron similar to ferritin $(1,15,28)$, leading to the protection of DNA from hydrogen peroxide radicals $(\mathrm{OH} \cdot)(15,27,28)$ produced from $\mathrm{H}_{2} \mathrm{O}_{2}$ by oxidative phosphorylation in the presence of $\mathrm{Fe}^{2+}$ by the Fenton reaction (15), it seems feasible that SEp22 binds and stabilizes DNA during the dehydration process, and also protects DNA, membranes and other cellular components from any reactive oxygen species produced during resuscitation of the dried, dormant Salmonella.

Next we examined the effects of nutritional factors on the acquisition of dry-resistance, because even a SEp22-positive clone, SECl\#15-1, failed to show resistance to the dry-proto- col when suspended in saline alone before the experiment (Fig. 4). To ascertain the effects of LB medium on the acquisition of the dry-resistance with (Fig. 1) or without (Fig. 4) LB medium, SECl\#15-1 was suspended in various concentrations of LB medium in saline, then subjected to drying. As shown in Fig. 6, the addition of only $10 \%$ of LB medium in saline increased the number of viable cells with the dry-protocol, showing that small amounts of nutritional factors enable $S$. Enteritidis to survive under dry conditions.

Then we tested whether foods induced dry-resistance. According to recent reports on food-poisoning in Japan, vegetables including green salads containing raw cabbage are sometimes responsible for diarrhea caused by $S$. Enteritidis. It seems feasible that cabbage leaves damaged by insects, storms or cutting during harvest, might secrete juice which supplies nutrients for $S$. Enteritidis and thus helps them to acquire dry-resistance. Other reports on the incidence of $S$. Enteritidis around poultry farms in Japan suggested that wild mice had brought the bacteria into Grading and Packaging centers (GP centers) where egg yolk or white had been spilled. Based on these reports, we tested the effects of egg yolk, egg white and raw cabbage extracts on the acquisition of dry-resistance by SECl\#15-1 cells. As shown in Fig. 7B, the egg yolk and cabbage extracts were effective in maintaining the viability of $S$. Enteritidis under dry conditions dependent on the dose: $0.496 \mu \mathrm{g} \mathrm{mL}^{-1}$ of yolk as a $5 \%$ solution yielded $23.9 \%$ viable bacteria, and $0.030 \mu \mathrm{g} \mathrm{mL}^{-1}$ of cabbage extract as a $5 \%$ solution yielded $1.42 \%$ viable bacteria. However, egg white was ineffective at maintaining viability above $0.1 \%$ of the initial level in spite of the high dose of $1.24 \mu \mathrm{g} \mathrm{mL}^{-1}$ of protein in the $20 \%$ solution, suggesting that the major components of egg white such as ovalbumin and lysozyme little facilitate the acquisition of dry-resistance by $S$. Enteritidis. Baron et al. $(3,4)$ suggested that natural egg white, containing ovotransferrin, limited the use of iron by Salmonella, leading to bacteriostatic effects on Salmonella, while spray-dried egg white did not suppress bacterial growth but stimulated it, probably due to the denaturation of ovotransferrin by heat-treatment during the manufacturing processes. In addition, supporting effects of bovine serum albumin on the maintenance of the viability of Salmonella Typhimurium were also reported (9).

The results of this study also imply that whether environmentally spreading $S$. Enteritidis, if it has the SEp22 protein, acquires dry-resistance or not is greatly influenced by the nutrients surrounding the bacteria before they are dried. This seems to provide a clue as to the determination of whether pathogenic Salmonella is killed or remains alive under drystress in foods, poultry farms, or other natural environments. In other words, keeping Salmonella away from nutrients before the dry-protocol is key to reducing contamination by bacteria. As shown in Fig. 7A, there were a variety of proteins included in egg yolk and cabbage extracts, and some of them seemed to have helped Salmonella to acquire dry-resistance (Fig. 7B). It should also be pointed out that there are other proteins that do not help Salmonella to survive under dry conditions (Fig. 7B), and we are trying to find such proteins in order to avoid Salmonella contamination of dry foods.

We also observed morphological changes of $S$. Enteritidis 
with the dry-protocol by scanning electron microscopy. As shown in Figs. 5B and 5D, the presence of LB before the dry-protocol resulted in the normal morphology of SECl\#151 being maintained, but that of saline alone did not (Figs. 5C and $5 \mathrm{E}$ ), suggesting the importance of nutritional factors to dry-resistance. It is not clear how fimbriae and/or flagella are involved in dry-resistance, but most of the bacteria in Fig. 5D and some of those in Fig. 5E showed protrusions like fimbriae and/or flagella during the rehydration process in the last stage of the dry-protocol. White et al. (24) suggested the involvement of fimbriae and cellulose in the enhancement of long-term survival of Salmonella under drying conditions, and Gibson et al. (7) suggested an important role of $O$ antigen capsule in the regulation of dry-resistance by $S$. Enteritidis through the formation of a fimbriae- and celluloseassociated extracellular matrix. Recently, Garmiri et al. (6) suggested a role for lipopolysaccharides in the protection of Salmonella Typhimurium from desiccation-related damage. It is not known whether SEp22, Salmonella Dps, participates in the regulation of extracellular matrix formation or lipopolysaccharide synthesis, as nutrients such as LB medium or casamino acids induced SEp22 expression in minimal medium in our previous studies (22).

We are currently studying in detail the mechanisms underlying the acquisition of dry-resistance by $S$. Enteritidis, focusing on the process by which water is lost, during which some biologically important molecules might undergo a change in organization from a semi-solid state to a solid state, and also in metabolism switching from an active state to a dormant state. The methods described in this paper will help us not only to develop analytical methods for studying bacterial dry-resistance but also to examine nutritional factors that promote or impede the acquisition of dry-resistance by $S$. Enteritidis, which will lead to ways of controlling foodpoisoning due to contamination by pathogenic bacteria.

\section{Acknowledgements}

This work was supported by grants from the Japan Health Sciences Foundation (KH51050 and KH51043), and by a Grant-in-aid for the Promotion of Science (15590117) and a Grant-in-aid for High Technology Research from the Ministry of Education, Science, Sports and Culture of Japan.

\section{References}

1. Almiron, M., A.J. Link, D. Furlong, and R. Kolter. 1992. A nove DNA-binding protein with regulatory and protective roles in starved Escherichia coli. Genes Dev. 6:2646-2654.

2. Assere, A., N. Qulahal, and B. Carpentier. 2008. Comparative evaluation of methods for counting surviving biofilm cells adhering to a polyvinyl chloride surface exposed to chloride or drying. J. Appl. Microbiol. 104:1692-1702.

3. Baron, F., M. Gautier, and G. Brule. 1999. Rapid growth of Salmonella Enteritidis in egg white reconstituted from industrial egg white powder. J. Food Prot. 62:585-591.

4. Baron, F., F. Nau, C. Guerin-Dublard, F. Gonnet, J.J. Dubois, and M. Gautier. 2003. Effect of dry heating on the microbiological quality, functional properties, and natural bacteriostatic ability of egg white after reconstitution. J. Food Prot. 66:825-832.

5. Center for Disease Control and Prevention (CDC). 2009. Multistate outbreaks of Salmonella infectious associated with live poultryUnited States. 2007. MMWR Morb. Mortal. Wkl. Rep. 58:25-29.

6. Garmiri, P., K.E. Coles, T.J. Humphrey, and T.A. Cogan. 2008. Role of outer membrane lipopolysaccharides in the protection of Salmonella enterica serovar Typhimurium from desiccation damage.
FEMS Microbiol. Lett. 281:155-159.

7. Gibon, D.L., A.P. White, S.D. Snyder, S. Martin, C. Heiss, P. Azadi, M. Surette, and W.W. Kay. 2006. Salmonella produces an $O$-antigen capsule regulated by AgfD and important for environmental persistence. J. Bacteriol. 188:7722-7730.

8. Halsey, T.A., A. Vazquez-Torres, D.J. Gravdahl, F.C. Fang, and S.J. Libby. 2004. The ferritin-like Dps protein is required for Salmonella enterica serovar Typhimurium oxidative stress resistances and virulence. Infect. Immun. 72:1155-1158.

9. Hirai, Y. 1991. Survival of bacteria under dry conditions; From a viewpoint of nosocomial infection. J. Hosp. Infect. 19:191-200.

10. Janning, B., P.H. In 't Veld, S. Notermans, and J. Kroemer. 1994 Resistance of bacterial strains to dry conditions: use of anhydrous silica gel in a desiccation model system. J. Appl. Bacteriol. 77:319324.

11. Kieboom, J., H.D. Kusumaningrum, M.H. Tempelaars, W.C. Hazeleger, T. Abee, and R.R. Beumer. 2006. Survival, elongation and elevated tolerance of Salmonella enterica serovar Enteritidis at reduced water activity. J. Food Prot. 69:2681-2686.

12. Kirby, R.M., and R. Davies. 1990. Survival of dehydrated cells of Salmonella typhimurium LT2 at high temperatures. J. Appl. Bacteriol. 68:241-246.

13. Laemmli, U.K. 1970. Cleavage of structural proteins during the assembly of the head of bacteriophage T4. Nature 227:680-685.

14. Lesn, J., S. Berthet, S. Binard, A. Rouxel, and F. Humbert. 2000 Changes in culturability and virulence of Salmonella typhimurium during long-term starvation under desiccating conditions. Int. J. Food Microbiol. 60:195-203.

15. Martinez, A., and R. Kolter. 1997. Protection of DNA during oxidative stress by the nonspecific DNA-binding protein Dps. J. Bacteriol 179:5188-5194.

16. Miki, T., N. Okada, and H. Danbara. 2004. Two periplasmic disulfide oxidoreductases, DsbA and $\mathrm{SrgA}$, target outer membrane protein SpiA, a component of the Salmonella pathogenicity island 2 type III secretion system. J. Biol. Chem. 279:34631-34642.

17. Monier, J.-M., and S.E. Lindow. 2003. Differential survival of solitary and aggregated bacterial cells promotes aggregate formation on leaf surfaces. Proc. Natl. Acad. Sci. USA 100:15977-15982.

18. National Institute of Infectious Diseases and Tuberculosis and Infectious Diseases Control Division, Ministry of Health, Labor and Welfare, Japan. 2006. Salmonellosis. IASR Infect. Agents Surveill. Rep. 27:191-192.

19. Pedersen, T.B., J.E. Olsen, and M. Bisgaard. 2008. Persistence of Salmonella Senftenberg in poultry production environments and investigation of its resistance to desiccation. Avian Pathol. 37:421427.

20. Roesicke, E., and E. Greuel. 1992. The survival ability of salmonella, coccidia oocysts and ascarid eggs in laying hen feces from different housing systems. Dtsch. Tierarztl. Wochenschr. 99:492-494.

21. Terai, S., M. Yamasaki, S. Igimi, and F. Amano. 2005. Expression and degradation of $S E p 22$, a pathogenicity-related protein of Salmonella Dps, in Salmonella Enteritidis isolated from the poultry farms in Japan. Biosci. Microflora 24:113-118.

22. Terai, S., M. Yasuda, and F. Amano. 2006. Regulation of SEp22 expression in Salmonella enterica subsp. enterica serovar Enteritidis by culture medium. Microbes Environ. 21:36-42.

23. VanCauwenberge, J.E., R.J. Bothast, and W.F. Kwolek. 1981. Thermal inactivation of eight Salmonella serotypes on dry corn flour. Appl. Environ. Microbiol. 42:688-691.

24. White, A.P., D.L. Gibson, W. Kim, W.W. Kay, and M.G. Surette. 2006. Thin aggregative fimbriae and cellulose enhance long-term survival and persistence of Salmonella. J. Bacteriol. 188:3219-3227.

25. White, A.P., and M.G. Surette. 2006. Comparative genetics of the rdar morphotype in Salmonella. J. Bacteriol. 188:8395-8406.

26. White, A.P., D.L. Gibson, G.A. Grassl, W.W. Kay, B.B. Finlay, B.A. Vallance, and M.G. Surette. 2008. Aggregation via the red, dry, and rough morphology is not a virulence adaptation in Salmonella enterica serovar Typhimurium. Infect. Immun. 76:1048-1058.

27. Wolf, S.G., D. Frenkiel, T. Arad, S.E. Finkel, R. Kolter, and A Minsky. 1999. DNA protection by stress-induced biocrystallization. Nature 400: 83-85.

28. Zhao, G., P. Ceci, A. Ilari, L. Giangiacomo, T.M. Laue, E. Chiancone, and N.D. Chasteen. 2002. Iron and hydrogen peroxide detoxification properties of DNA-binding protein from starved cells. A ferritin-like DNA-binding protein of Escherichia coli. J. Biol. Chem. 277:27689-27696. 